\title{
EFFICACY OF DIFFERENT THERAPEUTIC MODALITIES FOR PRIMARY MONOSYMPTOMATIC PEDIATRIC NOCTURNAL ENURESIS
}

\author{
Murtadha M Almusafer ${ }^{@}$ \& Aymen Adel* \\ ${ }^{\circledR}$ FICMS, Professor of Urology, University of Basrah, College of Medicine, Department of Surgery. \\ *FICMS, Urology Specialist, Basrah General Hospital, Basrah, IRAQ.
}

\begin{abstract}
Primary monosymptomatic nocturnal enuresis (PMNE) is still a common bothersome complaint that makes the children and their families looking for help. Primary MNE is defined as abnormal urination that occurs involuntarily during sleep. Its incidence varies with age, with 15\%-20\% at 5 year old and fades with increasing age to reach 1-2\% at 15 year old. Owing to its complicated pathophysiology and sharing of different body systems, multiple lines of treatment were attempted.

This study aimed is to explore the efficacy of different treatment modalities for PMNE in the study patients.

Ninety two patients were enrolled in this prospective randomized trial and divided into 4 groups; group A instructed to use the behavioral measures, group B given intranasal Desmopressin, group C given Oxybutynin and group D given combination of the 3 treatments. Fourteen participants were excluded because they were lost during followup and the remaining 78 patients' data were analyzed. Patients were reassessed at $4^{\text {th }}$ and $12^{\text {th }}$ weeks.

Wet nights/week significantly reduced in all treatment groups as compared to baseline. Percentage reduction of wet nights/week for behavioral group was 38.9\%, Desmopressin was $83 \%$, Oxybutynin was $78 \%$ and for Combination was $87.8 \%$ at $12^{\text {th }}$ week. According to the ICCS definitions of success there is no full response in behavioral group with partial response of $42.1 \%$, for Desmopressin group the full response was $57.1 \%$ and partial response $28.6 \%$, for Oxybutynin group was $50 \%$, and $33 \%$, for combination group $60 \%, 30 \%$ at $12^{\text {th }}$ week of treatment.

In conclusion, although behavioral therapy reduces wet nights but not reaching to a full improvement and its use is preferably combined with other treatment modalities. Desmopressin, Oxybutynin, and Combination treatment significantly decreases wet nights with high full response rate.
\end{abstract}

\section{Introduction}

$\mathrm{N}^{\mathrm{c}}$ octurnal enuresis (NE) is a common complaint in urology field and it affects a lot of children around the world ${ }^{1,2}$. Recurrence and treatment failure represent two main challenges in management of this disorder ${ }^{3}$. The International Children's Continence Society (ICCS) defines enuresis as an intermittent and involuntary passage of urine during sleep in five-year old and more children ${ }^{4}$. Nocturnal enuresis is classified into: Monosymptomatic nocturnal enuresis (MNE) and Nonmonosymptomatic nocturnal enuresis (NMNE). Monosymptomatic nocturnal enuresis means enuresis in children without history of bladder dysfunction or lower urinary tract symptoms (LUTS), it can be further divided into primary and secondary $^{5}$. Primary MSE defined as failure of a child to have adequate time of night dryness ${ }^{6}$. Secondary MSE defined as children with established enuresis after a period of dryness of six months ${ }^{7}$. The incidence rate is different in different age groups; it is estimated at 5 and 15 year old as (15-20\%) and (1-2\%) respectively ${ }^{8}$. The estimated spontaneous resolution rate is $15 \%$ per year ${ }^{9}$. Enuresis appears to involve boys more than girls with 2:1 ratio $^{10}$. Although the cause of $\mathrm{NE}$ is unclear, multiple body systems are 
thought to be involved, these systems include: the urinary bladder, kidney and brain $^{5}$. Urodynamic studies done during sleep found a significant bladder contraction rate in children with MSE as compared to those without ${ }^{11}$. It is stated that enuretic child have smaller bladder capacity than age matched control ${ }^{12}$. Other study found that the highest endurable bladder capacity was analogous between children with enuresis and controls during day time ${ }^{13}$. So it is useful to describe the bladder as functionally undersized.

Normally urine production is decreased at night time to half of that at day time due to the effect of antidiuretic hormone $(\mathrm{ADH})^{14}$. There are multiple proposed mechanisms for nocturnal polyuria in enuretic children and one of them is the effect of ADH circadian rhythm ${ }^{15}$. Other claimed mechanisms for increased urine formation at night may include greater fluid intake at the time before sleeping ${ }^{16}$, increased dietary solute load at evening which leads to increased urine osmolality $^{17}$, abnormal circadian rhythm of glomerular filtration rate ${ }^{18}$, obstructive sleep apnoea and hypoventilation ${ }^{19}$. It is important to know that not all children with enuresis have nocturnal polyuria ${ }^{20}$.

In healthy children, bladder distention and contractions are strong factors that induce awakening ${ }^{21}$. Enuretic children are often described as deep sleepers and they also have high threshold arousal and look more confused on awakening ${ }^{22}$. Although $\mathrm{NE}$ is a benign condition that may resolve as the child grows up, it may be associated with greater embarrassment and disappointment for the child ${ }^{23}$. Therefore, the goals of treatment are decreasing bed wetting nights, preventing wetting in special situations like sleepover and camping and preventing recurrence of the wetting ${ }^{24}$. Child willing and motivation are essential parts for starting successful treatment ${ }^{25}$. Treatment starts with reassuring and educating both child and parents. Many treatment modalities are attempted like behavioral therapy, alarm devices, medications (Desmopressin, Anticholinergic drugs, Tricyclic antidepressant,) and different combinations of these therapies ${ }^{26}$.

\section{Aim of study}

Till now no single effective treatment was prescribed for PMSE, so we design this study to assess the efficacy of available treatment modalities that are commonly used in the outpatient department like behavioral therapy, Desmoperssin, Oxybutynin, and combination of these modalities.

\section{Patients and Method}

This study was conducted from March to November 2016; it is a prospective randomized clinical study done for children attending urology outpatient clinic of Basrah General Hospital from Basrah and nearby provinces. The inclusion criteria were children with primary MNE with age from 6 to 14 years old. The exclusion criteria was any history of day time incontinence or lower urinary tract symptoms, neurological diseases, genitourinary system abnormality, urinary tract infection and diabetes mellitus. All patients were subjected to full history, physical examination, urinalysis, blood sugar measurement, and urinary system ultrasonography.

After confirmation of the diagnosis of PMNE, the total number of patients was 92. They were divided randomly by simple computer randomization into four groups each 23 cases. Group A received behavioral therapy, Group B given single dose of Desmopressin nasal spray of 20 microgram at night, group $\mathrm{C}$ given Oxybutynin $0.2 \mathrm{mg} / \mathrm{kg}$ three times daily and Group D given combination of the above treatment modalities. Fourteen patients were lost during followup (group A 4 patients, group B 2 patients, group C 5 patients and group $\mathrm{D} 3$ patients) and the remaining total number was 78 . All patients' parents were informed about the drugs taken by their children during the 
first visit regarding timing and possible side effects. The children were followed up and assessed at 4 and 12 weeks. The parents asked to make a tick in the follow up chart every morning about the wetting status of their child and possible undesirable effects of treatment. The efficacy of different treatment modalities at $4^{\text {th }}$ and $12^{\text {th }}$ week was assessed by: Number and percentage of reduction in wet night per week, the success rate was assessed according to ICCS definitions as: Full response, no wet nights (100\% reduction), partial response to treatment (50\%-99\% reduction in the number of enuresis per week), no response (less than $50 \%$ reduction in number of enuresis per week).

Statistical package for the social sciences (SPSS) program version 16 was used for assessment of study data. Demographic characteristics (age and sex) were described in term of mean and standard deviation. Comparison of quantitative data in between groups in form of reduced number of wet nights/week and percentage of reduction in wet nights/week at $4^{\text {th }}$ and $12^{\text {th }}$ week was done using One Way Anova with Post Hoc Analysis in term of mean (standard deviation). Qualitative data patient's responses in each group include (full response, partial response and no response) were compared by using Chi Square test. For all comparisons a $\mathrm{P}$ value of $<0.05$ considered statically significant.

\section{Results}

Demographic characteristics for each group including patient's number, mean age and gender are shown in table I, the final total number of patients was 78 . There was no significant difference in the age and sex between the different groups.

Table I: Demographic characteristics in each group of patients

\begin{tabular}{|l|c|c|c|c|c|}
\hline & Behavioral & Desmopressin & Oxybutynin & Combination & $\begin{array}{c}\text { P } \\
\text { value }\end{array}$ \\
\hline $\begin{array}{l}\text { Patient } \\
\text { No. }\end{array}$ & 19 & 21 & 18 & 20 & \\
\hline $\begin{array}{l}\text { Age yrs. } \\
\text { Mean } \pm \text { SD }\end{array}$ & $9.8 \pm 2.3$ & $9.2 \pm 2.5$ & $8.8 \pm 2.0$ & $10 \pm 2.7$ & 0.424 \\
\hline Gender & $57.9 \% \mathrm{M}$ & $66.7 \% \mathrm{M}$ & $66.7 \% \mathrm{M}$ & $60 \% \mathrm{M}$ & 0.916 \\
\cline { 2 - 6 } & $41.1 \% \mathrm{~F}$ & $33.3 \% \mathrm{~F}$ & $33.3 \% \mathrm{~F}$ & $40 \% \mathrm{~F}$ & \\
\hline
\end{tabular}

By term of significance, there was significant reduction in mean number of wet nights/week in each treatment group at $4^{\text {th }}$ and $12^{\text {th }}$ week as compared with start of study ( $P$ value $<0.0005$ ) as shown in
Table II. However there was no significant difference when comparing mean number of wet nights/week between $4^{\text {th }}$ and $12^{\text {th }}$ week ( $\mathrm{P}$ value $>0.0005$ ) for all treatment groups.

Table II: Reduction in mean number of wet nights

\begin{tabular}{|l|c|c|c|c|}
\hline \multicolumn{1}{|c|}{ Group } & $\begin{array}{c}\text { Start } \\
\text { mean } \pm \text { SD }\end{array}$ & $\begin{array}{c}\mathbf{4}^{\text {th }} \text { week } \\
\text { mean } \pm \text { SD }\end{array}$ & $\begin{array}{c}\mathbf{1 2}^{\text {th }} \text { week } \\
\text { mean } \pm \text { SD }\end{array}$ & P value \\
\hline Behavioral & $4.63 \pm 1.42$ & $2.78 \pm 0.48$ & $2.57 \pm 0.5)$ & $<0.0005$ \\
\hline Desmopressin & $5.23 \pm 1.26$ & $1.04 \pm 1.26$ & $0.76 \pm 0.94$ & $<0.0005$ \\
\hline Oxybutynin & $5.33 \pm 1.13$ & $1.5 \pm 1.42$ & $1.3 \pm 1.8$ & $<0.0005$ \\
\hline Combination & $5.1 \pm 1.33$ & $1.4 \pm 1.66$ & $0.7 \pm 0.8$ & $<0.0005$ \\
\hline
\end{tabular}

The overall percentage of reduction in wet nights/week for each group is shown in table III. 
Table III: Percentage of reduction in wet nights/week

\begin{tabular}{|l|l|l|}
\hline \multicolumn{1}{|c|}{ Group } & \% reduction at $\mathbf{4}^{\text {th }}$ week & \% reduction at $\mathbf{1 2}^{\text {th }}$ week \\
\hline Behavioral & 33.6 & 38.9 \\
\hline Desmopressin & 77.4 & 83.1 \\
\hline Oxybutynin & 74.3 & 78.1 \\
\hline Combination & 75.1 & 87.8 \\
\hline
\end{tabular}

By analysis, behavioral group showed significant lower percentage of reduction of wet nights/week at both $4^{\text {th }}$ and $12^{\text {th }}$ week as compared with other treatment modalities ( $\mathrm{P}$ value $<0.0005)$. However there was no significant difference in between Desmopressin, Oxybutynin, and Combination groups. The response rate according to the ICCS definitions of treatment success is shown in Table IV.

Table IV: Percentage of response at $4^{\text {th }}$ and $12^{\text {th }}$ weeks for each group (ICCS)

\begin{tabular}{|c|c|c|}
\hline Group & $4^{\text {th }}$ week & $12^{\text {th }}$ week \\
\hline \multicolumn{3}{|c|}{ Behavioral } \\
\hline Full response (\%) & 0 & 0 \\
\hline Partial response (\%) & 21.1 & 42.1 \\
\hline No response (\%) & 78.1 & 57.9 \\
\hline \multicolumn{3}{|c|}{ Desmopressin } \\
\hline Full response (\%) & 47.6 & 57.1 \\
\hline Partial response (\%) & 28.6 & 28.6 \\
\hline No response (\%) & 23.8 & 14.3 \\
\hline \multicolumn{3}{|c|}{ Oxybutynin } \\
\hline Full response (\%) & 33.3 & 50 \\
\hline Partial response (\%) & 50 & 33.3 \\
\hline No response (\%) & 16.7 & 16.7 \\
\hline \multicolumn{3}{|c|}{ Combination } \\
\hline Full response (\%) & 50 & 60 \\
\hline Partial response (\%) & 20 & 30 \\
\hline No response (\%) & 30 & 10 \\
\hline
\end{tabular}

Minor adverse side effects were developed, in Desmopressin group (nasal irritation in 2 patients, in Oxybutynin group (dry mouth in 2 patients, constipation in 2 patients), and in Combination group (nasal irritation in 1 patient, constipation in 1 patient, dry mouth in 2 patients).

\section{Discussion}

This research designed to study the efficacy of behavioral modulations, Desmopressin, Oxybutynin, and the combination of the three treatment options on primary monosymptomatic nocturnal enuresis. The efficacy was assessed by total reduction in number of nights/week, percentage of reduction in wet nights and response rate of different therapeutic modalities according to international continence society (ICCS) values of success. Although behavioral therapy considered first treatment option and its efficacy was mentioned to be better than no treatment ${ }^{27}$, the response found in many studies was variable. A recent study by Erol et al in Turkey showed a full response rate at 1 month and 1 year in $40 \%, 54 \%$ respectively, partial response in $10 \%$ and $8 \%$ and no response in $52 \%$, $38 \%{ }^{28}$. Another study done by Robson showed a full response in $22 \%$ and partial response in $39 \%{ }^{29}$, also Baeynes found a full response rate in $24 \%$ only $^{30}$. In a 
study on Egyptian children, full response was $35 \%$, partial response was $30 \%$ done by Farida in $(2015)^{31}$. However, in this study there is a diversity in results and it reveals no full response rate $(0 \%)$, partial response in $42 \%$ and no response in $57 \%$, this may be explained by the nonadherence of the patients with the instructions given to them owing to different cultural and social background of the families and those children need more visits to the clinic for insuring their family application of and adherence to the given instructions. Also a longer duration of applying the behavioral modulation measures is needed to assess the efficacy of them. It is wisely to ask about the efficacy of behavioral therapy and bladder training, Cederblad (2015) found that these measures not significantly reduce wet nights ${ }^{32}$.

With Desmopressin therapy this study shows comparable response rate with many other studies and reviews like $\mathrm{T}$. Naveus et al (2010) with 30\% full response and $40 \%$ partial response ${ }^{33}$. Also in small number (40 child) study done in Egypt at 2015 response to Desmopressin was $45 \%$ respond fully and $25 \%$ respond partially $^{31}$. Fai-Nago (2005) found a full response in $31 \%$ and partial response in $39 \%{ }^{34}$,While in this study response was $57 \%$ fully and $28 \%$ partially with slightly more full response, and total response $81 \%$ which is also higher than the studies above but lower in study done by G. Bolla (2014) that showed 97\% response rate ${ }^{35}$. The relapse rate was not assessed in this study owing to short time of follow up and not intended initially.

The use of anticholinergic drugs as monotherapy is conflicting and its efficacy is questionable ${ }^{36}$. As mentioned in some studies it can be used in patients with diurnal enuresis or if treatment with DDPVA failed. Anticholinergics can be combined with DDPVA or used alone with response rate range from $47 \%$ to $71 \%{ }^{37,38}$. These drugs best used in patients with hyperreflexic and restricted bladder capacity ${ }^{37}$.

Although in this study we did not assess bladder capacity, Oxybutynin showed full response rate of $50 \%$ and parietal response rates of $33 \%$ at 3 months (total response $83 \%$ ) which is a promising results, these results are nearly similar to a study results done in Iran 2015 Seyfhashemi et al showed 71\%response to Oxybutynin at 6 weeks follow up ${ }^{39}$. Yeung et al. found that patients with nocturnal enuresis who had abnormal bladder functional capacity at daytime may show a decrease in the capacity at night; this may explain a better response to Oxybutynin ${ }^{40}$.

Combination group with Oxybutynin and Desmopreesin achieved highest success rate and significant reduction in wet nights when compared with other treatment in this study. However the response was comparable to Desmopressin. In a study done at 2001 combination of Desmopressin and Oxybutynin was associated with more improvement in $50 \%$ of patients ${ }^{41}$. Although we use standard dose of Oxybutynin with Desmopressin and we got good results, Berkenwald (2016) found that increasing dose of Oxybutynin associated with more success than using standard dose $^{42}$, therefore, combination of these drugs preserved to failure of single treatment ${ }^{38}$.

\section{Conclusions and Recommendations}

This study results showed a diversity regarding the use of behavioral therapies as these therapies did not effectively treat enuresis and their effectiveness should be asked. The use of Desmopressin is associated with acceptable improvement. Oxybutynin administration showed good results and may be promoted to use as first line single monotherapy for primary nocturnal enuresis and adding Oxybutynin to Desmpressin have a high success rate, but should be used for failure of either above drug monotherapy.

We recommend a longer duration of follow up with larger patient's sample. 


\section{References}

1. Shreeram S, He JP, Kalaydjian A, et al. Prevalence of enuresis and its association with attention-deficit/hyperactivity disorder among U.S. children: results from a nationally representative study. J Am Acad Child Adolesc Psychiatry 2009;48:35-48

2. Wolfe-Christensen C, Kovacevic LG, Mirkovic J, et al. Lower health related quality of life and psychosocial difficulties in children with monosymptomatic nocturnal enuresis: is snoring a marker of severity? J Urol 2013;190:1501-1504.

3. Pedaiatric Urology, second edition, chapter 29, page380 Philadelphia, Sunders Elsevier,2010.

4. Austin PF, Bauer SB, Bower W, et al. The standardization of terminology of lower urinary tract function in children and adolescents: update report from the Standardization Committee of the International Children's Continence Society. Neurourol. Urodynam. 9999:1-11, 2015.

5. Campbell Walsh urology, eleventh edition, chapter 143, page 3311 Philadelphia, Elsevier Inc.,2016.

6. Friman PC, Warzak WJ. Nocturnal enuresis: a prevalent, persistent, yet curable parasomnia. Pediatrician 1990;17:38-45.

7. Von Gontard A, Mauer-Mucke K, Plück J, et al. Clinical behavioral problems in day and night-wetting children. Pediatr Nephrol 1999;13:662-7.

8. Kiddoo D. Nocturnal enuresis. BMJ Clin Evid. 2011;2011.

9. Forsythe WI, Redmond A. Enuresis and spontaneous cure rate: st+udy of 1129 enuretics. Arch Dis Child 1974;49:259-263.

10. Yeung CK, Sihoe JDY, Sit FKY, et al. Characteristics of primary nocturnal enuresis in adults: an epidemiological study. BJU Int 2004b;93:341-345.

11. Nrgaard JP, Hansen JH, Wildschitz G, et al. Sleep cystometries in children with nocturnal enuresis. J Urol 1989b;141:1156-9.

12. Starfield B. Functional bladder capacity in enuretic and nonenuretic children. J Pediatr 1967;70:777-81.

13. Kawauchi A, Tanaka Y, Naito Y, et al. Bladder capacity at the time of enuresis. Urology 2003;61:1016-8.

14. Rittig S, Kamperis K, Siggard C, et al. Age-related nocturnal urine volume and maximum voided volume in healthy children: reappraisal of International Children's Continence Society definitions. J Urol 2010;183:1561-7.

15. Robson WL. Clinical practice: evaluation and management of enuresis. N Engl J Med 2009;360:1429-36.

16. Robson WL. Enuresis. Adv Pediatr 2001;48:409-38.

17. Dehoorne JL, Raes AM, van Laecke E, et al. Desmopressin resistant nocturnal polyuria secondary to increased nocturnal osmotic excretion. J Urol 2006;176:749-53.

18. De Guchtenaere A, Vande Walle C, Van Sintjan P, et al. Nocturnal polyuria is related to absent circadian rhythm of glomerular filtration rate. J Urol 2007;178:2626-9.

19. Su MS, Li AM, So HK, et al. Nocturnal enuresis in children: prevalence, correlates, and relationship with obstructive sleep apnea. J Pediatr 2011; 159:238-42.

20. Steffens J, Metzer M, Isenberg E, et al. Vasopressin deficiency in primary nocturnal enuresis: results of a controlled prospective study. Eur Urol 1993;24:366-70.

21. Koyama Y, Imada N, Kayama Y, et al. How does the distention of urinary bladder cause arousal? Psychiatry Clin Neurosci 1998;52:142-5.

22. Nevéus T, Hetta J, Cnattingius S, et al. Depth of sleep and sleep habits among enuretic and incontinent children. Acta Paediatr 1999a;88:748-52.

23. Jalkut MW, Lerman SE, Churchill BM. Enuresis. Pediatr Clin North Am2001:48:1461-88.

24. Sinha R et al. Management of nocturnal enuresis. Myths and facts... World J Nephrol. 2016 July 6; 5(4): $328-338$.

25. Ramakrishnan K. Evaluation and treatment of enuresis. Am Fam Physician. 2008;78(4):489-96.

26. DiBianco JM, Morley C, Al-Omar O. Nocturnal enuresis: a topic review and institution experience. Avicenna J Med. 2014;4(4):77-86

27. DREW C. BAIRD. Enuresis in Children: A Case-Based Approach .Am Fam Physician. 2014;90(8):560-568

28. Meltem Erol.Motivation Therapy in Children with Primary Monosymptomatic Nocturnal Enuresis Med Bull Haseki 2016:54:7-12

29. Robson LM, Leung AK. Urotherapy recommendations for bedwetting J Natl Med Assoc 2002;94:577-80.

30. Baeyens D, Lierman A, Roeyers H, Hoebeke P, Vande Walle J. Adherence in children with nocturnal enuresis. J Pediatr Urol 2009;5:105-9.

31. Farida EIBaz. Assessment of the efficacy of desmopressin in treatment of Primary Nocturnal Enuresis in Egyption children. The Egyption Journal of Medical Human Genetics.2015:16:257-262.

32. Cederblad M, Sarkadi A, Engvall G, Nevéus T. No effect of basic bladder advice in enuresis: A randomized controlled trial. .jpurol.2015.03.004.

33. Nevéus T, Eggert P, Evans J, et al. Evaluation of and treatment for monosymptomatic enuresis: a standardization document from the International Children's Continence Society. J Urol 2010;183:441-7.

34. Fai-Ngo Ng C, Wong SN, Hong Kong Childhood Enuresis Study Group. Comparing alarms, desmopressin, and combined treatment in Chinese enuretic children. Pediatr Nephrol 2005;20:163-9.

35. Giorgio Bolla. Different Therapeutical Attitudes against Enuresis the Prosecution of a Clinical Experience. American Journal of Clinical Medicine Research, 2014;2:2, 51-52

36. Deshpande AV, Caldwell PH, Sureshkumar P. Drugs for nocturnal enuresis in children (other than desmopressin and tricyclics). Cochrane Database Syst Rev 2012;(12):CD002238.

37. Montaldo P, Tafuro L, Rea M, et al. Desmopressin and oxybutynin in monosymptomatic nocturnal enuresis: a randomized, double-blind, placebo-controlled trial and an assessment of predictive factors. BJU Int 2012;110:E3816.

38. Austin PF, Ferguson G, Yan Y, et al. Combination therapy with desmopressin and an anticholinergic medication for nonresponders to desmopressin for monosymptomatic nocturnal enuresis: randomized, double-blind, placebocontrolled trial. Pediatrics 2008;122:1027-32.

39. Seyfhashemi M et al. Desmopressin, Imipramine, and Oxybutynin in the Treatment of Primary Nocturnal Enuresis: A Randomized Clinical Trial. Iran Red Crescent Med J. 2015 July; 17(7): e16174.

40. Yeung CK, Sit FK, To LK, Chiu HN, Sihoe JD, Lee E, et al. Reduction in nocturnal functional bladder capacity is a common factor in the pathogenesis of refractory nocturnal enuresis. BJU Int. 2002;90(3):302-7.

41. Neveus T. Oxybutynin, distance and enuresis. J Urol. 2001;166(6):2459-62.

42. Berkenwald A, Pires J, Ellsworth. Evaluating use of higher dose oxybutynin in combination with desmopressin for refractory nocturnal enuresis. J Pediatr Urol. 2016 Aug;12(4):220.e1-6. 